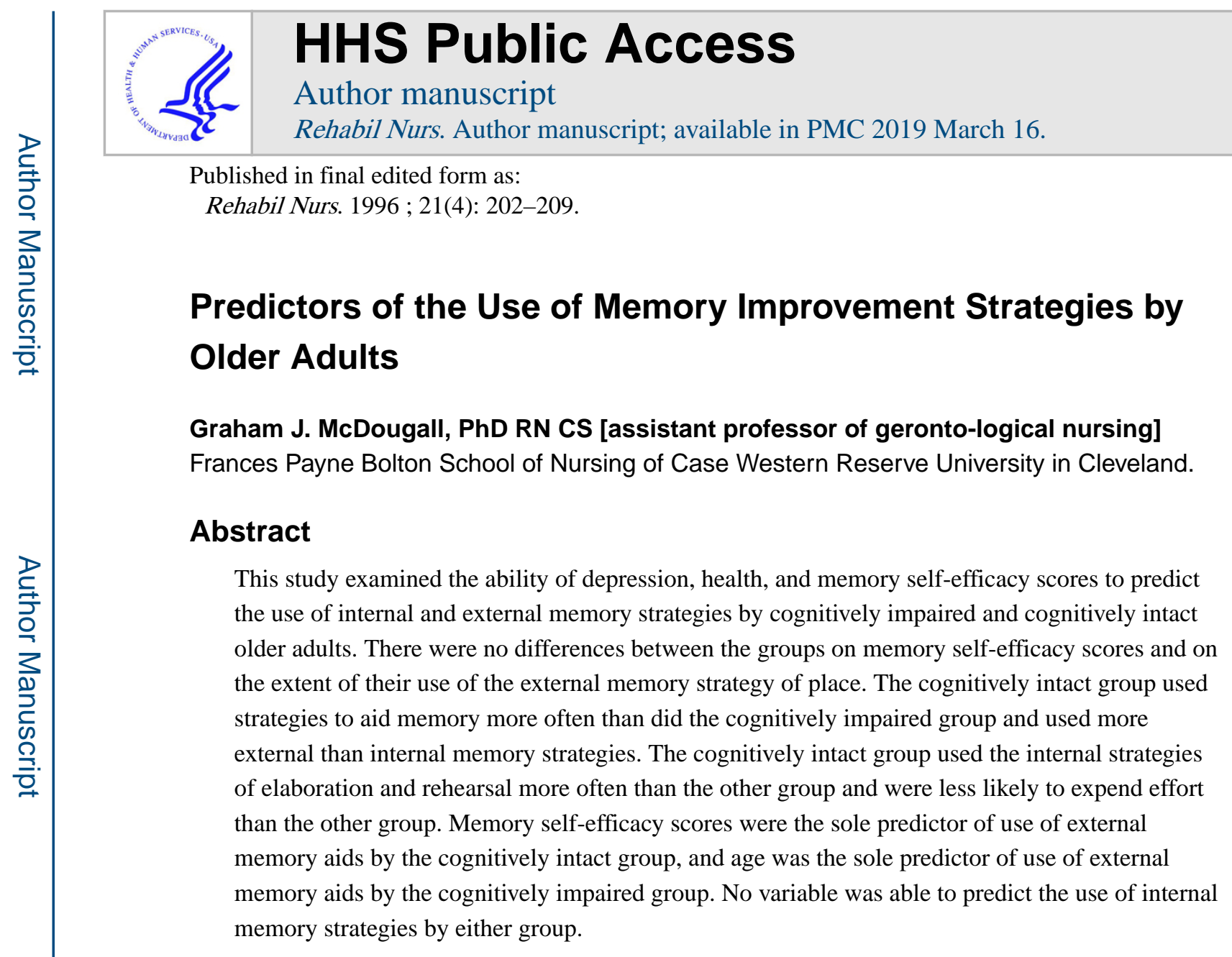

The elderly population of the United States, approximately 31.6 million people as estimated by the 1990 census (U.S. Bureau of the Census, 1991), represents a challenge to rehabilitation professionals because of the cognitive losses that occur with normal aging. There is an ongoing interest in aging adults' memory and use of memory aids, because the majority of older adults' cognitive complaints involve forgetfulness and self-reported memory problems (Herrmann, 1990; Poon, 1985). One U.S. study reported that $15 \%$ of participants 55 years of age or older $(N=14,783)$ had had memory problems within the previous year (Cutler \& Grimes, 1988).

While $95 \%$ of the elderly population live in the community setting, the nation's nursing home population increased by $24.2 \%$ from 1980 to 1990 . Nearly 1.8 million people lived in nursing homes in 1990; of these, 1.6 million were 65 or older (U.S. Bureau of the Census, 1992). Cognitive impairments, primarily dementias, are prevalent and may include a mix of affective disorders, such as anxiety and depression (Bums et al., 1988; Rovner \& Katz, 1993). Elderly persons' complaints about memory problems not only provide information about how they view their own cognitive abilities but also may help rehabilitation professionals distinguish dementia from depression (Gilewski \& Zelinski, 1986). Thus, an accurate understanding of cognitive function and specific knowledge about memory and memory perceptions are necessary prerequisites for rehabilitation professionals who

Address correspondence to Graham J. McDougall, PhD RN CS, Assistant Professor of Gerontological Nursing, Frances Payne Bolton School of Nursing, Case Western Reserve University, 10900 Euclid Avenue, Cleveland, OH 44106-4904. 
encourage self-care and participation in rehabilitation programs (Beck, 1990; Benedict, 1989; Ben-Yishay \& Diller, 1993). The purpose of this study, therefore, was to examine the ability of depression, health, and memory self-efficacy to predict the use of internal and external memory strategies by cognitively intact and cognitively impaired elders.

\section{Relevant literature}

Both younger and older adults use strategies—knowingly and unknowingly - to improve their ability to remember (Brigham \& Pressley, 1988). Such memory strategies are broadly classified as either internal (e.g., repeating names) or external (e.g., making a list) (Sugar, 1992). An individual not only must monitor and choose appropriate memory strategies but also must believe he or she has the ability, or self-efficacy, to carry out memory tasks without undue anxiety in demanding situations (Bandura, 1991; Devolder \& Pressley, 1992; Dittmann-Kohli, Lachman, Kliegl, \& Baltes, 1991). An individual's performance is determined by the cognitive demands of the situation, the perception of likely outcomes, and the use of both internal and external memory aids (Hultsch, Herzog, \& Dixon, 1987).

Older adults want to improve their everyday memories in specific domains that are of concern; these include remembering people's faces and names, important dates and telephone numbers, names of common objects, recent and past events, meetings and appointments, general information and facts, and directions (Bolla, Lindgren, Bonaccorsy, \& Bleecker, 1991; Harris, 1980; Leirer, Morrow, Sheikh, \& Pariante, 1990). Studies have demonstrated that in their everyday lives older adults use memory strategies less often than younger adults (Byrd, 1986; Perlmutter, 1988). When memory strategies are used, they are more often external than internal (Hill, Allen, \& Gregory, 1990; Intons-Peterson \& Fournier, 1986; McDougall, 1995a). However, if given appropriate instructions, older adults are capable of using strategies to improve their memory performance. Those older adults who use a well-articulated mnemonic outperform older adults who use repetition of simple associations (Hill et al.).

Depression and anxiety may moderate the effects of age on an individual's perception of his or her memory performance (McDougall, 1993, 1994,1995b; Zelinski, Gilewski, \& Anthony-Bergstone, 1990). In studies in which the relationship between the memory complaint and the memory performance was not supported, the investigators either excluded individuals who were depressed or used no measure of depression. In a memory training study with younger and older adults, Weaver and Lachman (1989) observed that older adults who had minor depression became more accurate in their performance predictions over time than those who had major depression. In the National Health Interview Survey of 1984, it was determined that self-ratings of health accounted for $17 \%$ of the variance in self-assessed memory scores (National Center for Health Statistics, 1986).

Investigators have reported that self-efficacy beliefs may influence mnemonic training outcomes for participants attending memory-improvement classes (Rebok \& Balcerak, 1989; Rebok \& Offerman, 1983; Seeman, Rodin, \& Albert, 1993). That is, even though memory training may not improve actual performance, stronger belief in one's self-efficacy may be beneficial. Perceptions of one's ability to remember are known as memory self-efficacy. 
Low memory self-efficacy has adverse consequences (Bandura, 1991; Berry \& West, 1994); the cognitive repercussions can include a generally negative self-concept and the perception that almost everyone else has a better memory. The behavioral consequences can include shopping for a physician to cure the cognitive problem, purchasing expensive medications in an effort to increase memory, avoiding social interactions that involve recalling names, and losing motivation and perseverance in memory-demanding situations and tasks.

My study examined the association of health, depression, and memory self-efficacy scores with the internal and external memory strategies used by cognitively intact and cognitively impaired older adults in an effort to predict the use of memory-facilitation strategies by elderly people. The study was approved by a university institutional review board and by the administration of the nursing homes that were involved.

\section{Method}

Subjects:

Cognitively intact subjects.-The cognitively intact sample was drawn from two sites, one in Louisiana (Site A) and one in Texas (Site B), that offered continuing education programs for older adults. At Site A, I gave a series of presenta tions about the research in classes attended by potential subjects, and I invited their participation in the project. Questionnaire packets and self-addressed, stamped envelopes were distributed to individuals who agreed to participate, and they returned the completed questionnaires with signed consent forms. The return rate for Site A was 54\%, or 125 participants.

At Site B, a brief description of the study and a sign-up list were posted on a bulletin board. I called each individual who signed the list and described the study. Survey packets were mailed to those who were interested. The participants returned the completed questionnaires in stamped, self-addressed, envelopes. The return rate for Site B was 100\%, or 44 participants. The participants from sites A and B were presumed to be cognitively intact; they were not screened for level of cognitive function because all were attending continuing education programs, living in their own homes, and driving automobiles.

Cognitively impaired subjects.-The cognitively impaired sample was composed of adults 59 years of age or older residing in five long-term care facilities in Cleveland. I received lists of individuals with possible cognitive impairments from the nursing staff and approached these residents to ask them to participate in the study. The adults were considered a captive population and were approached with the utmost consideration. Informed consent was obtained prior to their participation in the study, and subjects were free to refuse to participate or to discontinue their participation at any time. All of these participants were able to sign consent forms. Their participation or lack of participation was kept confidential. In order to avoid diagnostic ambiguity, I determined a participant's level of cognitive impairment with screening instruments known to be reliable and valid (McDougall, 1990). The cognitively impaired sample had to meet two criteria: (a) to have Mini-Mental State Examination (MMSE) scores of between 15 and 23 and (b) to have Global Deterioration Scale scores of 2 or 3. 


\section{Materials:}

Five instruments were used in this study: the Mini-Mental State Examination (Folstein, Folstein, \& McHugh, 1975), the Global Deterioration Scale (Reisberg, Gordon, \& McCarthy, 1985), the Geriatric Depression Scale (Brink et al., 1982), the Health Scale, a subscale of the Multilevel Assessment Instrument (Lawton, Moss, Fulcomer, \& Kleban, 1982), and the four subscales of the Metamemory in Adulthood questionnaire (Dixon, Hultsch, \& Hertzog, 1988).

Mini-Mental State Examination.-Individuals were first screened by their taking the MMSE to determine the presence or absence of cognitive impairment and, if present, its severity. The MMSE contains 11 questions, with scores ranging from 0 to 30 . A score of 23 or lower indicates cognitive impairment. Usually a score between 18 and 22 indicates mild cognitive impairment, and a score between 0 and 17 indicates severe cognitive impairment (Pearson, Cherrier, \& Teri, 1989; Tombaugh \& McIntyre, 1992). However, Phillips, Chu, Morris, and Hawes (1993) determined that among residents of nursing homes, the average MMSE score for the cognitively impaired was 9.97 and the average score for the cognitively intact was 21.34. Individuals scoring above 23 and below 15 on the MMSE were excluded from the cognitively impaired sample. Individuals with MMSE scores within this accepted range were screened with the Global Deterioration Scale.

Global Deterioration Scale.-This scale, which is used to determine the degree of cognitive decline, has seven clinically identifiable stages, ranging from 1, indicating no cognitive decline, to 7, indicating very severe cognitive decline. It is not until Stage 4 that individuals show deficits on the Mental Status Questionnaire. The Global Deterioration Scale has been validated against behavioral, neuroanatomic, neurophysiologic, and psychometric measures for patients with primary degenerative dementia. Individuals with scores of 2 or 3 were included in my study as these stages represent the clinical characteristics of cognitive decline: Stage 2 is very mild cognitive decline, and Stage 3 is mild cognitive decline. (The alpha reliability cannot be determined for this instrument.)

Geriatric Depression Scale.-Depression was measured by using the 15 -item short version of the Geriatric Depression Scale. Scores range from 0 to 15 , with a score of 5 or more indicating depression. Any score on this scale was acceptable for the participants in the study. The Geriatric Depression Scale correlates highly with other depression measures, and its authors reported an alpha reliability coefficient of .94 and a split-half reliability of .94 (Parmelee, Lawton, \& Katz, 1989; Sheikh \& Yesavage, 1986; Yesavage et al., 19.83). In my study, the alpha coefficient was .83 for the cognitively impaired group and .73 for the cognitively intact group.

Health Scale.-This scale measured health status. Subjects rated their health using a 3- to 4-point response format, with anchors that ranged from better to not so good and from excellent to poor. There are four questions, and total scores can range from 4 to 13, with higher scores indicating better health. Any score on this scale was acceptable for participation in the study. Lawton et al. (1982) reported an alpha coefficient of .76 and a testretest correlation of .92. Chronic conditions and prescription medications that might cause or 
simulate dementia were recorded and included as predictor variables. The alpha was .61 for the cognitively impaired group and .75 for the cognitively intact group.

Metamemory in Adulthood (MIA) questionnaire.-The MIA is a measure of the memory components of knowledge, beliefs, and affect. It is not a screening device for actual memory problems. The MIA consists of 108 statements, which are rated on a 5-point Likert scale. The 7 subscales measure strategy, task, capacity, change, anxiety, achievement, and locus. Each of the dimensions emphasizes ecologically relevant or everyday memory activities.

In this study, memory self-efficacy was measured by the capacity subscale of the MIA, which measures a person's perception of his or her memory capacities by predictive selfreport of performance on given tasks (higher scores = higher capacity) (Dixon, 1989; McDonald-Miszczak, Hertzog, \& Hultsch, 1995). This subscale contains 17 items. Numerous investigations have determined that the subscale accurately measures memory self-efficacy (Dixon et al., 1988; McDonald-Miszczak et al.). The alpha coefficient was .80 for the cognitively impaired group and .85 for the cognitively unimpaired group.

Change, as defined in the MIA, is the perception of a person's own memory abilities as generally being stable or as subject to long-term decline (higher scores = stability). The change subscale in the MLA contains 18 items. Locus is the individual's perceived personal control over remembering abilities (higher scores $=$ internal locus). The locus subscale contains 9 items. Strategy is knowledge of a person's own methods to improve memory performance, including reported use of internal and external strategies. This subscale contains 18 items (higher scores $=$ high use).

Internal strategies are mental or cognitive manipulations; external strategies are memory devices in the environment used to facilitate remembering. Internal strategies in the MIA include rehearsal (4 items), elaboration (4 items), and effort ( 1 item). Rehearsal strategies for basic learning tasks usually involve repeating the names of items in an ordered list. In the MIA, an example of a question related to an internal rehearsal strategy is "Do you consciously attempt to reconstruct the day's events in order to remember something?" Elaboration strategies for basic learning tasks include forming a mental image or a sentence relating items in one category to those in another. An example of an elaboration strategy question in the MIA is "When you try to remember people you have met, do you associate names and faces?" The effort question is "Do you try to concentrate hard on something you want to remember?"

External memory strategies in the MIA are related to the use of calendars ( 1 item), lists (2 items), notes ( 3 items), place ( 2 items), and help from another person ( 1 item). An example of a note-strategy question is "When you finish reading a book or magazine, do you somehow note the place where you have stopped?" An example of a place-strategy question in the MIA is "Do you routinely keep things in a familiar spot so you won't forget them when you need to locate them?" An example of a calendar-strategy question is "Do you write appointments on a calendar to help you remember them?" An example of a personstrategy question is "Do you ask other people to remind you of something?" 
The MIA's psychometric characteristics have been examined with community-dwelling middle-aged and older adults. In a study of community-residing elderly people, I reported (1994) that Cronbach's alpha varied considerably for different subscales, ranging from .73 to .95 . Intercorrelations between the MIA subscales range from extremely low (-.05) to moderate (.60) (Dixon et al., 1988). The coefficient alphas for the cognitively impaired group were .85 on the change subscale, .57 on the locus subscale, .72 on the strategy subscale, and .80 on the capacity subscale. The coefficient alphas for the cognitively intact group on these subscales were .92 for change, .79 for locus, .85 for strategy, and .85 for capacity.

\section{Results}

For the cognitively intact sample, the overall return rate was 54\% for Site A and $100 \%$ for Site B. The nonprobability sample consisted of 128 females (76\%) and 41 males (24\%) 55 years and older. The great majority of the participants were white $(96 \%)$, and the remainder were black. Forty-one percent $(n=69)$ of the individuals were married; 37\% $(n=63)$ were widowed; $10 \%(n=17)$ were divorced; and 12\% $(n=20)$ had never married. Subjects ranged in age from 55 to 83 years old. The males were significantly younger than the females. Seventy percent of the subjects belonged to at least two organizations, and many belonged to five. Yearly incomes were reported by 100 participants (59\%) and ranged from $\$ 3,000$ to $\$ 450,000$; of these 100,73 had yearly incomes between $\$ 3,000$ and $\$ 33,000$. Only three individuals had yearly incomes of more than $\$ 83,000$ per year.

The cognitively impaired population sample was composed of 55 adults, age 59 or older, residing in five long-term care facilities in the greater Cleveland area; 90\% were female and 96\% were white. Seven percent $\{n=4)$ of the individuals were married; $80 \%(n=44)$ were widowed; $6 \%(n=3)$ were divorced; and $7 \%(n=4)$ had never married. The mean age was 87.24 years ( $S D=7.73$ years) for the women, and 86.0 years ( $S D=9.14$ years) for the men. To achieve a final sample, 100 residents were screened. Of these, 12 residents received diagnoses indicating an actual or potential disturbance in cognition (dementia for 6 , cerebrovascular accident for 2, and Parkinson's disease for 4). The participants had numerous chronic conditions and all were taking both prescription and over-the-counter medications. Eleven of the 55 were specifically taking medications either for anxiety (6) or depression (5). Twenty-eight (51\%) of the 55 subjects were depressed and 27 (49\%) had low scores (5-8) on the health status scale.

The results of unpaired $t$ tests indicated that the cognitively impaired group was significantly $(p<.001)$ different from the other group on several variables. They were older, had more chronic illness, took more prescription and over-the-counter medications, reported being in worse health, and more of them had depression. The cognitively impaired group had a mean score of 5.5 on the depression scale; the cognitively intact group's mean score of 1.9 indicated no overall depression, although 7 of them received a score of 5.0 or more on the depression inventory. There were no group differences on memory self-efficacy scores. On the metamemory factors, the cognitively impaired group scored significantly lower on the change, locus, and strategy subscales $(p<.001)$. Pearson correlations between age and 
strategy scores (-.31), depression and capacity scores (-.44), and depression and change scores $(-.41)$ were statistically significant $(p \leq .05)$.

Based on recent evidence in the literature (Crum, Anthony, Bassett, \& Folstein, 1993; Grut et al., 1993) on cognitive differences, exploratory analyses were implemented. Due to the uneven distribution of the variables and the small sample size, the Mann-Whitney $U$ test was used to test for significant differences between the mildly impaired $(n=47)$ and severely $(n$ $=8$ ) impaired. These analyses produced significant findings for four variables. The severely impaired had lower MMSE scores (15.88) than the mildly impaired (20.96), used fewer over-the-counter medicines ( 0.50 vs. 1.81 ), used more memory strategies (3.61 vs. 3.19), and used more internal strategies (3.75 vs. 3.18). When comparisons were repeated for the same variables, but the severely impaired subjects were excluded, the results were virtually identical. Therefore the results for the cognitively impaired group are reported as an aggregate.

Given the high incidence of depression (51\%) in the cognitively impaired group, exploratory analyses of the group were computed with $t$ tests on major study variables by using the presence of depression $(n=28)$ or absence of depression $(n=27)$ as the division criterion. The findings were significant for three variables. The depressed subgroup was significantly older ( 86.43 years vs. 80.11 years) and scored lower on the metamemory factors of capacity (3.00 vs. 3.33 ) and change (2.37 vs. 2.72$)$.

\section{Memory aids used by the cognitively intact group:}

The results of $t$ tests indicated that the cognitively intact group used significantly more external memory strategies $(\mathrm{M}=3.75)$, such as notes and lists, than internal strategies $(\mathrm{M}=$ $3.47)$, such as effort, elaboration, and rehearsal $(t[157]=5.474, p \leq .0001)$. Of the external strategies, aids involving place were used more often than lists or notes. Of the internal memory strategies, the cognitively intact adults used significantly more rehearsal $(M=3.63)$ than elaboration $(M=3.29)$ strategies $(t[168]=6.37, p<.0001)$. There were no differences between the groups on the total scores of internal memory strategies.

Simultaneous multiple regression analyses were conducted to study the effects of age in conjunction with the study variables (depression, health, and memory self-efficacy) on external strategy use. In each regression, age was entered first, but did not meet the entry criteria for inclusion. In step two, analyses were conducted to determine whether the addition of depression, health, and memory self-efficacy scores would increase the amount of explained variance. The set of study variables in step two accounted for $6 \%$ of the variance in external strategy scores for the cognitively intact group (see Table 1).

Multiple regression analyses were also conducted to study the effects of demographic variables in conjunction with the study variables (depression, health, and memory selfefficacy scores) on internal strategy use. Again, age was entered first in each regression equation; however, it did not meet the entry criteria for inclusion. In step two, demographic variables and the study variables of depression, health, and self-efficacy were entered. No set of variables met the entry criteria. 


\section{Memory aids used by the cognitively impaired group:}

Of the internal memory strategies, the cognitively impaired group identified using significantly more effort (3.91) than the intact group (3.62) as an internal memory strategy $(p<.05)$. However, since only one question ("Do you try to concentrate hard on something you want to remember?") related to effort was asked, the validity of this finding is questionable. The cognitively impaired group scored lower on the use of all external memory strategies $(M=3.15)$, except for the place strategy $(M=4.03)$. As was expected, cognitively impaired individuals used fewer external strategies than internal strategies ( $M=$ 3.42).

Simultaneous multiple regression analyses were conducted to study the effects of demographic variables in conjunction with the study variables (cognitive level, depression, health, and memory self-efficacy scores) on external strategy use. In the first regression, age was entered first; it predicted $10 \%$ of the variance in scores on use of external strategies. In step two, age and cognitive level were entered. Together, the demographic and cognitive level variables accounted for $11 \%$ of the variance in external strategy subscale scores. In step three, analyses were conducted to determine whether the addition of depression, health, and memory self-efficacy would increase the amount of variance explained. They accounted for $0 \%$ of the variance in external strategy scores. The addition of the study variables did not increase the overall $R^{2}$ in the external strategy scores of the cognitively impaired group (see Table 2). Age was the only predictor of external strategy use in the impaired group.

Multiple regression analyses were also conducted to study the effects of demographic variables in conjunction with the study variables (cognitive level, depression, health, and memory self-efficacy) on internal strategy use. In the first regression, age was entered; however, it did not meet the entry criteria. In step two, age and cognitive level were entered; together, they did not meet the entry criteria. In step three, analyses were conducted to determine whether the addition of depression, health, and memory self-efficacy scores would increase the amount of variance explained. No combination of the demographic and study variables predicted the internal strategy sub-scale scores for the cognitively impaired group.

\section{Discussion}

Memory self-efficacy was the sole predictor of external memory strategy use by the cognitively intact group (see Table 1). Self-efficacy in Bandura's model $(1989,1991)$ is based on a person's judgment about how well he or she can organize and execute courses of action required to deal with prospective and unpredictable situations, some of which may be ambiguous and stress-producing. In the early phase of learning a new behavior, repeated failures lower efficacy expectations more if the failures do not reflect a lack of effort (Berry $\&$ West, 1994). Individuals who have less confidence may give up because of doubts about their ability to achieve a desired level of performance, or they may be convinced of their abilities but give up because of an unresponsive or punishing environment. In this study, there were no differences in memory self-efficacy scores between the cognitively impaired and the intact groups even though memory self-efficacy was the sole predictor of external memory aid use by the cognitively intact group. 
This finding was not expected, given the $80 \%$ incidence of memory concerns of older adults reported in the literature and the fact that the cognitively intact older individuals were attending educational classes. While many older adults cite memory loss and forgetfulness as a problem, they seem to choose to do nothing about it. Perhaps this "do-nothing" attitude is a function of lack of knowledge, of symptoms that do not interfere with daily activities, or of attributing the problem to the aging process. The do-nothing attitude in response to memory lapses and memory failures may be related to lack of knowledge, little education, or both, rather than to low self-efficacy as there were no significant differences in the selfefficacy measures of either group in this study. Furthermore, the capacity scale of the MIA may not àctually measure memory self-efficacy as recommended by Bandura (1989), because both level and strength of memory performance predictions must be determined. However, the use of a less complicated measurement is beneficial with older adults, particularly with those who have cognitive impairment. The restriction of variance in response may undermine the predictive power of the measurement (Maibach \& Murphy, 1995).

There were significant differences between the two study groups on levels of depression. Investigators have hypothesized that cognitively impaired and cognitively intact elderly people with depression will use memory strategies more often than elderly people without depression (Gilewski, Zelinski, \& Schaie, 1990; O'Connor, Pollitt, Roth, Brook, \& Reiss, 1990). This was not supported in my study, in which the correlations between use of strategies and cognitive impairment and depression were not statistically significant. The prediction was supported, however, for the severely impaired group (those with MMSE scores of less than 17). Participants with severe cognitive impairment used more internal memory strategies (3.75 vs. 3.18) and more total memory strategies (3.61 vs. 3.19$)$ than the mildly impaired group used. However, the severely cognitively impaired group was made up of only 8 individuals. A significant clinical finding is uncertain with such a small number of subjects.

In the cognitively impaired group, of note were the inverse correlations between depression and memory capacity scores and depression and change scores. A high score on the capacity subscale is positive, indicating greater memory capacity. A high score on the change subscale is also positive, indicating stability or not being subject to decline. The inverse correlation between memory capacity and depression indicates that as depression decreased, the perception of memory capacity increased. Also, as depression decreased, subjects' perception of memory change moved toward stability. Depression, therefore, appears to have a strong and direct influence on the memory perceptions of cognitively impaired elderly people.

\section{Nursing implications}

Are cognitive loss and mental deterioration preventable in old age? If the answer is yes, what methods can help prevent them from occurring? As noted earlier, education has always been considered an important means of remaining mentally fit. In fact, during the 1830s and 1840 s, the object of education was to enlarge the mind and train its powers. Faculty psychology, or the view that the mind consists of separate faculties or powers that are 
developed and improved by exercise, permeated the curriculum (Tanner \& Tanner, 1995). Further, at the turn of the century, faculty psychology became the basis for the mentaldiscipline model of education. Believers in the mental-discipline model were convinced that individuals must continuously use their mental faculties and strengthen them through rigorous exercise or lose them. The "use it or lose it" view of learning is still held by many educational philosophers, particularly the perennialists and essentialists, who believe that Latin, mathematics, and other classical liberal studies are the best methods for training the mind. This belief in mental training extends to any mental task the learner may confront. Even though faculty psychology is considered outmoded, many people continue to believe that the best approach to remaining cognitively healthy is through mental discipline.

Thus, the question is whether education or interventions to promote cognitive health will help prevent or delay the mental losses that occur in normal aging. There has been continuous growth in educational offerings for older adults since the first Boston-based Elderhostel program opened in 1975, and older adults are attending all types of classes in record numbers (Beck \& Glick, 1991; Ventura-Merkel \& Doucette, 1993). Older adults enroll in educational activities for many reasons; however, the majority are attending classes for the joy of learning and for a personal challenge (Chen, 1987; Lumsden, 1988). Continued development of knowledge about the older adult learner will be helpful in education, community, and healthcare settings.

Cognitive screening of elderly patients should become a routine part of any health assessment, regardless of the setting. Accuracy of memory assessments would be strengthened by including assessments of metamemory, memory self-efficacy, and depression, because these factors can possibly affect the people's perceptions of their cognitive abilities. For the large numbers of older adults living in nursing homes in the United States, accurate knowledge about cognitive function and, more specifically, about memory is a necessary prerequisite for encouraging self-care and participation in cognitive rehabilitation programs.

\section{Acknowledgments}

This paper was presented at the June 1994 meeting of the American Academy of Nurse Practitioners in Washington, DC, and at the November 1994 meeting of the Gerontological Society of America in Atlanta. The research was supported by the American Nurses Foundation and by a Biomedical Research Support Grant. The author acknowledges Elizabeth Tomquist, MA, for her helpful comments on drafts of the manuscript.

\section{References}

Bandura A (1989). Regulation of cognitive processes through perceived self-efficacy. Developmental Psychology, 25,729-735.

Bandura A (1991). Self-efficacy mechanism in physiological activation and health-promoting behavior In Madden J, IV (Ed.), Neurobiology of learning, emotion, and affect (pp. 229-269). New York: Raven Press.

Beck C (1990). Cognitive rehabilitation in the elderly. Physical Medicine and Rehabilitation, 4(1), 2937.

Beck M, \& Glick D (1991, 11 11). School days for seniors.Newsweek, pp. 60-65. [PubMed: 10114358] 
Benedict RHB (1989). The effectiveness of cognitive remediation strategies for victims of traumatic head-injury: A review of the literature. Clinical Psychology Review, 9, 605-626.

Ben-Yishay Y, \& Diller L (1993). Cognitive remediation in traumatic brain injury: Update and issues. Archives of Physical Medicine and Rehabilitation, 74, 204-213. [PubMed: 8431107]

Berry JM, \& West RL (1994). Cognitive self-efficacy in relation to personal mastery and goal setting across the life span. International Journal of Behavior Development, 16, 351-379.

Bolla KI, Lindgren KN, Bonaccorsy C, \& Bleecker ML (1991). Memory complaints in older adults. Archives ofNeurology, 48, 61-64.

Brigham MC, \& Pressley M (1988). Cognitive monitoring and strategy choice in younger and older adults. Psychology and Aging, 3, 249-257. [PubMed: 3268266]

Brink TL, Yesavage JA, Lum O, Heersema PH, Adey M, \& Rose TL (1982). Screening tests for geriatric depression. Clinical Gerontologist, 1(1), 37-43.

Bums BJ, Larson DB, Goldstrom ID, Johnson WE, Taube CA, Miller NE, \& Mathis ES (1988). Mental disorders among nursing home patients: Preliminary findings from the national nursing home survey pretest. International Journal of Geriatric Psychiatry, 5,27-35.

Byrd M (1986). The use of organizational strategies to improve memory for prose passages. International Journal of Aging and Human Development, 23,257-265. [PubMed: 3557640]

Chen YP (1987). Making assets out of tomorrow's elderly. The Gerontologist, 27,410-416. [PubMed: 3623132]

Crum RM, Anthony JC, Bassett SS, \& Folstein MF (1993). Population-based norms for the MiniMental State Examination by age and educational level. Journal of the American Medical Association, 269,2386-2391. [PubMed: 8479064]

Cutler SJ, \& Grimes AE (1988). Correlates of self-reported everyday memory problems. Journal of Gerontology, 43(3), S82-S90. [PubMed: 3361099]

Devolder PA, \& Pressley M (1992). Causal attributions and strategy use in relation to memory performance differences in younger and older adults. Applied Cognitive Psychology, 6, 629-642.

Dittmann-Kohli F, Lachman ME, Kliegl R, \& Baltes P (1991). Effects of cognitive training and testing on intellectual efficacy beliefs in elderly adults. Journal of Gerontology, 46(4), 162-164.

Dixon RA (1989). Questionnaire research on metamemory and aging: Issues of structure and function In Poon LW, Rubin DC, \& Wilson BA (Eds.), Everyday cognition in adulthood and late life (pp. 394-415). New York: Cambridge University Press.

Dixon RA, Hultsch DF, \& Hertzog C (1988). The Metamemory in Adulthood (MIA) questionnaire. Psychopharmacology Bulletin, 24,671-688. [PubMed: 3249770]

Folstein MF, Folstein SE, \& McHugh PR (1975). "Mini-mental state": A practical method for grading the cognitive-state of patients for the clinician. Journal of Psychiatric Research, 12,189-198. [PubMed: 1202204]

Gilewski MJ, \& Zelinski EM (1986). Questionnaire assessment of memory complaints In Poon LW (Ed.), Handbook for clinical memory assessment of older adults (pp. 93-107). Washington, DC: American Psychological Association.

Gilewski MJ, Zelinski EM, \& Schaie KW (1990). The Memory Functioning Questionnaire for assessment of memory complaints in adulthood and old age. Psychology and Aging, 5,482-490. [PubMed: 2278670]

Grut M, Jorm AF, Fratiglioni L, Forsell Y, Vitanen M, \& Winblad B (1993). Memory complaints of elderly people in a population survey: Variation according to dementia stage and depression. Journal of the American Geriatrics Society, 41,1295-1300. [PubMed: 8227910]

Harris JE (1980). Memory aids people use: Two interview studies. Memory and Cognition, 8(1), 3138.

Herrmann DJ (1990). Self-perceptions of memory performance In Rodin J, Schooler C, \& Schaie KW (Eds.), Self-directédness: Cause and effects throughout the life course (pp. 199-211). Hillsdale, NJ: Lawrence Erlbaum.

Hill RD, Allen C, \& Gregory K (1990). Self-generated mnemonics for enhancing free recall performance in older learners. Exper imental Aging Research, 16(3), 141-145. 
Hultsch DF, Herzog C, \& Dixon R (1987). Age differences in metamemory: Resolving the inconsistencies. Canadian Journal of Psychology, 41(2), 193-208. [PubMed: 3502896]

Intons-Peterson MJ, \& Fournier JA (1986). External and internal memory aids: When and how often do we use them? Journal of Experimental Psychology: General, 3, 267-280.

Lawton MP, Moss M, Fulcomer M, \& Kleban MH (1982). A research and service oriented multilevel assessment. Journal of Gerontology, 57(1), 91-99.

Leirer VO, Morrow DG, Sheikh JI, \& Pariante GM (1990). Memory skills elders want to improve. Experimental Aging Research, 16(3), 155-158. [PubMed: 2090468]

Lumsden DB (1988). How adults learn. Generations, 12,10-15.

Maibach E, \& Murphy DA (1995). Self-efficacy in health promotion research and practice: Conceptualization and measurement. Health Education Research: Theory and Practice, 70(1), 3750.

McDonald-Miszczak L, Hertzog C, \& Hultsch DF (1995). Stability and accuracy of metamemory in adulthood and aging: A longitudinal analysis. Psychology and Aging, 10, 553-564. [PubMed: 8749582]

McDougall GJ (1990). A review of screening instruments for assessing cognition and mental status in older adults. The Nurse Practitioner, 75(11), 18-20, 22-24, 26-28.

McDougall GJ (1993). Older adults' metamemory: Coping, depression, and self-efficacy. Applied Nursing Research, 5(1), 28-30.

McDougall GJ (1994). Predictors of metamemory in older adults. Nursing Research, 43(4), 212-218. [PubMed: 8047425]

McDougall GJ (1995a). Memory self-efficacy and strategy use in successful elders. Educational Gerontology, 21, 357-373.

McDougall GJ (1995b). Metamemory and depression in cognitively impaired elderly. Nursing Research, 44, 306-311. [PubMed: 7567487]

National Center for Health Statistics. (1986). Aging in the eighties: Preliminary data from the Supplement to the National Health Interview Survey, U.S., January-June 1984. Advance Data from Vital \& Health Statistics, 115,1-8.

O’Connor DW, Pollitt PA, Roth M, Brook PB, \& Reiss BB (1990). Memory complaints and impairment in normal, depressed, and demented elderly persons identified in a community survey. Archives of General Psychiatry, 47, 224-227. [PubMed: 2306164]

Parmelee PA, Lawton MP, \& Katz IR (1989). Psychometric properties of the Geriatric Depression Scale among the institutionalized aged. Psychological Assessment: A Journal of Consulting and Clinical Psychology, 1, 331-338.

Pearson JL, Cherrier M, \& Teri L (1989). The mini-mental state exam and the mental status questionnaire: Depression in Alzheimer's disease. Clinical Gerontologist, 5(4), 31-37.

Perlmutter M (1988). Cognitive potential throughout life In Birren JE \& Bengston VL (Eds.), Emergent theories of aging (pp. 247-268). New York: Springer Publishing.

Phillips CD, Chu CW, Morris JN, \& Hawes C (1993). Effects of cognitive impairment on the reliability of geriatric assessments in nursing homes. Journal of the American Geriatrics Society, 41(2), 136142. [PubMed: 8426035]

Poon LW (1985). Differences in human memory with aging: Na ture, causes, and clinical implications In Birren JE \& Schaie KW (Eds.), Handbook of the psychology of aging (2nd ed.; pp. 427-462). New York: Van Nostrand.

Rebok GW, \& Balcerak LJ (1989). Memory self-efficacy and performance differences in young and old adults: The effect of mnemonic training. Developmental Psychology, 25,714-721.

Rebok GW, \& Offerman LR (1983). Behavioral competencies of older college students: A self-efficacy approach. The Gerontolo-gist, 23, 428-432.

Reisberg B, Gordon B, \& McCarthy M (1985). Insight and denial accompanying progressive cognitive decline in normal aging and Alzheimer's disease In Stanley BS (Ed.), Geriatric psychiatry: Clinical, ethical and legal issues (pp. 37-79). Washington, DC: American Psychiatric Association.

Rovner BW, \& Katz IR (1993). Psychiatric disorders in the nursing home: A selective review of studies related to clinical care. International Journal of Geriatric Psychiatry, 8, 75-87. 
Seeman TE, Rodin J, \& Albert M (1993). Self-efficacy and cognitive performance in high-functioning older individuals. Journal of Aging and Health, 5,455-474.

Sheikh JI, \& Yesavage JA (1986). Geriatric Depression Scale (GDS): Recent evidence and development of a shorter version. Clinical Gerontologist, 5(1/2), 165-173.

Sugar JA (1992). Memory, learning, and attention In Birren JE, Sloane RB, \& Cohen GD (Eds.), Handbook of mental health and aging (2nd ed.; pp. 307-337). San Diego: Academic Press.

Tanner D, \& Tanner LN (1995). Curriculum development (3rd ed.). New York: Macmillan.

Tombaugh TN, \& McIntyre NJ (1992). The Mini-Mental State Examination: A comprehensive review. Journal of the American Geriatrics Society, 40, 922-935. [PubMed: 1512391]

Ventura-Merkel C, \& Doucette D (1993). Community colleges in an aging society. Educational Gerontology, 19, 161-171.

U.S. Bureau of the Census. (1991). Current population survey. Washington, DC: Author.

U.S. Bureau of the Census. (1992). Census of the population and housing: 1990 public use micro data samples. Washington, DC: Technical Documentations.

Weaver SL, \& Lachman ME (1989, 8). Enhancing memory self-conceptions and strategies in young and old adults In Hill RD \& Berry $\mathrm{J}$ (Chairs), What is memory training the training of? Symposium conducted at the meeting of the American Psychological Association, New Orleans.

Yesavage JA, Brink TL, Rose TL, Lum O, Huang V, Adey M, \& Leirer VO (1983). Development and validation of a geriatric depression screening scale: A preliminary report. Journal of Psychiatric Research, 17(1), 37-49.

Zelinski EM, Gilewski MJ, \& Anthony-Bergstone CR (1990). Memory Functioning Questionnaire: Concurrent validity with memory performance and self-reported memory failures. Psychology and Aging, 5, 388-399. [PubMed: 2242243] 
Table 1.

Multiple Regression Analyses of the Relation of Demographic and Study Variables to the External Strategy Subscale in the Cognitively Intact Group $(n=169)$

\begin{tabular}{lcccccc}
$\begin{array}{l}\text { Predictor } \\
\text { Variable } \\
\text { Entered }\end{array}$ & $\boldsymbol{R}$ & $\boldsymbol{R}^{2}$ & Adj. $\boldsymbol{R}^{2}$ & $\boldsymbol{\beta}$ & $\boldsymbol{F}$ \\
& \multicolumn{7}{c}{} \\
$\begin{array}{l}\text { Memory } \\
\text { Self-Efficacy }\end{array}$ & .25 & .06 & .04 & -.21 & 6.85 \\
\hline
\end{tabular}


Table 2.

Multiple Regression Analyses of the Relation of Demographic and Study Variables to the External Strategy Subscale in the Cognitively Impaired Group $(n=55)$

\begin{tabular}{lllllll}
$\begin{array}{l}\text { Predictor } \\
\text { Variable } \\
\text { Entered }\end{array}$ & $\boldsymbol{R}$ & $\boldsymbol{R}^{2}$ & $\mathrm{Adj} . \boldsymbol{R}^{2}$ & $\boldsymbol{\beta}$ & $\boldsymbol{F}$ \\
\multicolumn{7}{c}{ External Strategy Subscale } \\
Age & .33 & .11 & .07 & -.29 & 4.86 \\
\hline
\end{tabular}

